\title{
Advanced engineering design capabilities applied for developing a technological device for automated assembly
}

\author{
Ionut Madalin Pista $^{1 *}$, Vasile Merticaru, Gheorghe Nagit ${ }^{1}$, and Marius Ionut Ripanu ${ }^{1}$ \\ 1“Gheorghe Asachi” Technical University of Iasi, Department of Machine Manufacturing \\ Technology, Prof. D. Mangeron Street, no. 39A, Iasi, Romania
}

\begin{abstract}
The theoretical approach and the related case study presented in the paper are part of a larger research regarding the optimization of assembled products and assembly processes by enhancing the effectiveness and efficiency of design activities, including by embedment of DfX/DFMA principles. First of all, a conceptual model for the theoretical approach is proposed and discussed. The case study refers to the engineering design of an indexing mounting table for automated assembly of an electrical plug inlet. Some advanced principles and theories are discussed in relation to the technical solution design. Advanced engineering design capabilities provided by Solid Edge have been used for solving the 3D modelling task and for the other detailed design activities. Finally, some related conclusions are included, together with some directions of further researches.
\end{abstract}

\section{Introduction. Problem statement}

Within the NPD (New Product Development) process in general, an appropriated detailed establishment of product requirements and their translation into product specifications are of vital importance for aligning the best design solution to the client needs, [1]. One could consider that those product design activities cover mainly the Concept Design phase and System-Level Design phase from the design process, [2].

An advanced design philosophy, which we consider useful to be applied in the Concept Design phase and being able to facilitate the selection of the most adequate product concept solution among various others is the Axiomatic Design (AD), developed by Suh, [3].

For the System-Level Design phase, there can be considered as appropriated the involvement of DfX (Design for Excellence) design philosophy, [4], mainly DFMA (Design for Manufacturing and Assembly), [5], being important for an optimized development of assembled products and assembly processes.

The theoretical approach and the related case study presented in the paper are part of a larger research regarding the optimization of assembled products and assembly processes by enhancing the effectiveness and efficiency of design activities, including by embedment of some Axiomatic Design and DfX/DFMA principles.

${ }^{*}$ Corresponding author: ionutpista@yahoo.com 


\section{Conceptual model of the research approach}

First of all, a conceptual model for the theoretical approach is proposed, as in Figure 1.

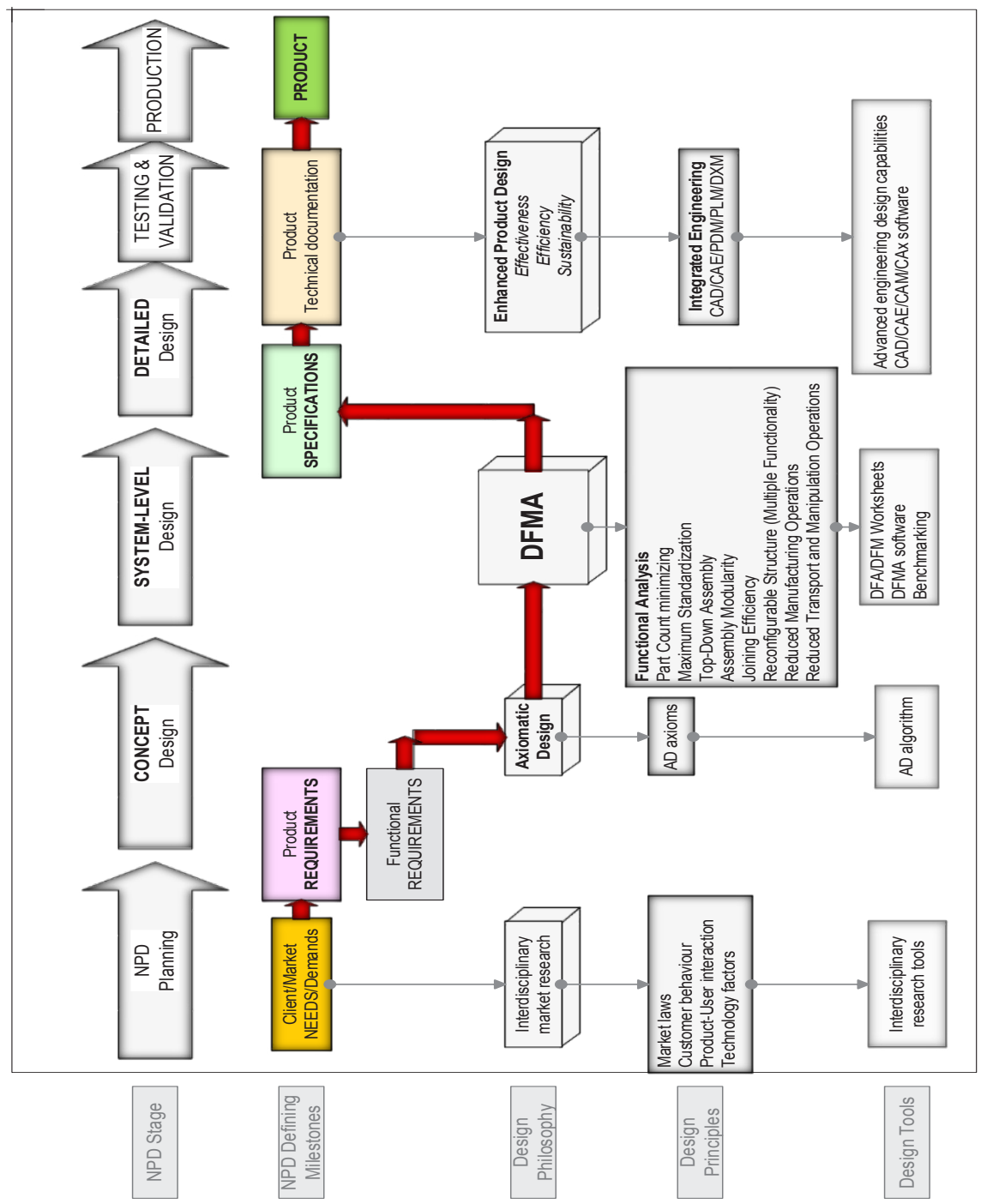

Fig. 1. Conceptual model of the research approach.

Within the model, an exhaustive interdisciplinary market research is recommended for defining the client/market needs/demands, which are translated into product requirements. Among those, the functional requirements have been mainly considered within the research approach, as input for the $\mathrm{AD}$ study, where the two $\mathrm{AD}$ axioms (axiom of independence and axiom of information) have been considered as design principles. The four domains of the theory are proposed to be covered within the AD study, for sequentially establishing the customer's requests, the functional requirements, the design structural parameters and respectively the process variables. Based on the recommendations of Stienstra, [6], the following principles are considered for the DFMA study: Functional Analysis; Part Count minimizing; Maximum Standardization; Top-Down Assembly; Assembly Modularity; 
Joining Efficiency; Reconfigurable Structure (Multiple Functionality); Reduced Manufacturing Operations; Reduced Transport and Manipulation Operations.

For the Detailed Design phase, within the philosophy of Enhanced Product Design by effectiveness, efficiency and sustainability, the principles of Integrated Engineering, respectively those of $\mathrm{CAD} / \mathrm{CAE} / \mathrm{PDM} / \mathrm{PLM} / \mathrm{DXM}$ are considered $[7,8]$, where: $\mathrm{CAD}-$ Computer Aided Design, CAE - Computer Aided Engineering, PDM - Product Data Management, PLM - Product Lifecycle Management, DXM - Data Exchange Management.

\section{Case study}

The case study refers to the engineering design of an indexing mounting table for automated assembly of an electrical plug inlet. For applying the algorithm and the principles highlighted in the previously presented conceptual model, the considered assembled product has been first of all analysed.

\subsection{Assembled product description}

The assembled product subjected to study, respectively an industrial electrical plug inlet, is shown in Figure 2, where the 3D view, the exploded view and the assembly scheme for it are presented.
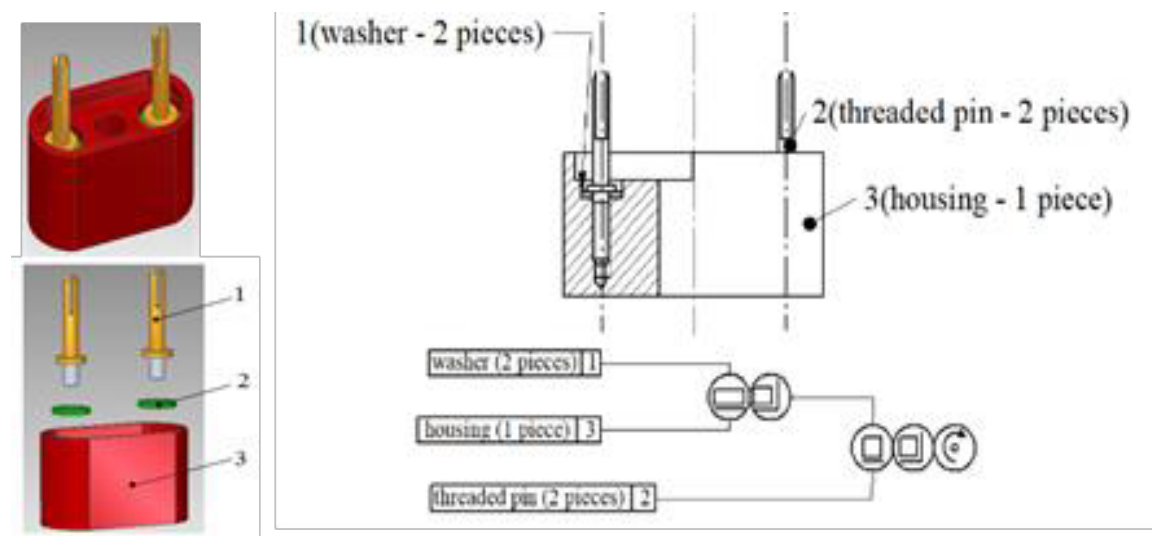

Fig. 2. 3D view, exploded view and assembly scheme for the studied assembled product.

\subsection{Concept design for the indexing mounting table}

Within the Axiomatic Design study, the following customer needs have been identified: CN1: the device could be achieved within a laboratory for automated assembly, or within an assembling workshop from an electrical equipment factory;

CN2: constructive simplicity and component availability, in conditions of maximal productivity.

Further on, the main functional requirement has been established, as following:

FRO: design a technological device for automated assembly of an electrical plug inlet, adaptable for a laboratory for automated assembly, or for an assembling workshop from an electrical equipment factory, in conditions of cost effective manufacturing and assembly.

A set of second order functional requirements has been also established and those have been decomposed in third order functional requirements. In relation to the above mentioned 
functional requirements, a set of design parameters were identified, corresponding to the constructive structure of the designed indexing mounting table, as shown in Figure 3.

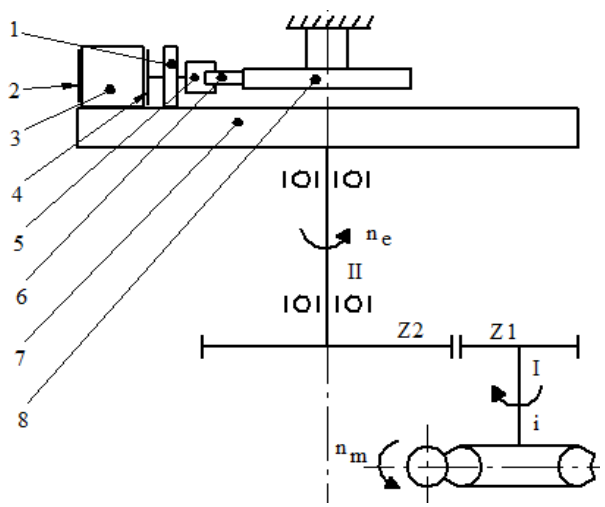

Fig. 3. Conceptual design scheme for the indexing mounting table. 1 - guiding element; 2 - orienting prism; 3 - plug inlet; 4 - fixing jaw; 5 - follower rod; 6 - roller; 7 - rotating plate; 8 - cam.

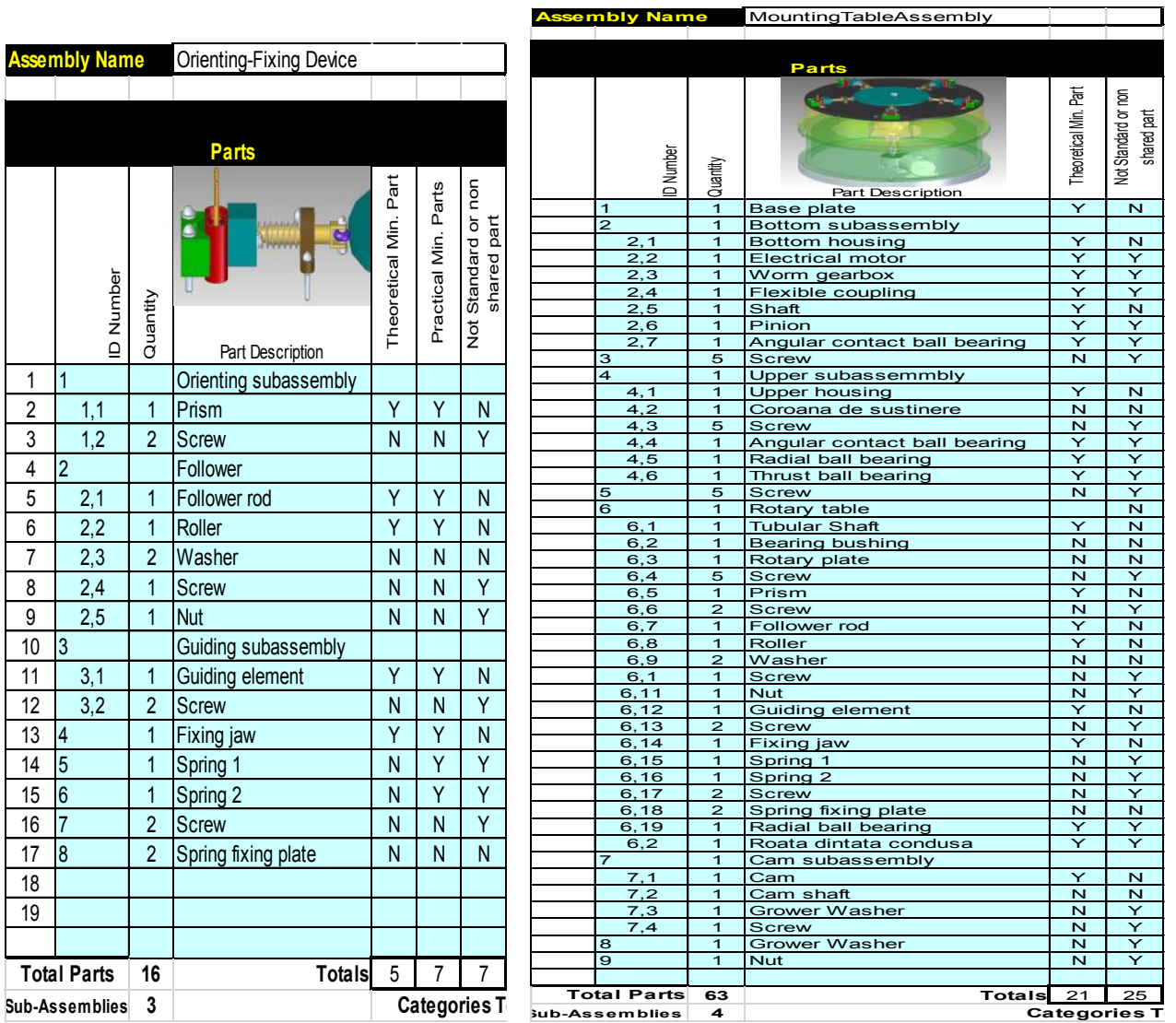

Fig. 4. DFA worksheets (partial view) for the Mounting Table assembly and for the Orienting-Fixing subassembly. 


\subsection{System level design for the indexing mounting table}

By the embedment of DfX/DFMA principles within the research approach case study, a set of DFMA worksheets, [9], have been completed for the Mounting Table assembly and for the Orienting-Fixing subassembly.

\subsection{Detailed design for the indexing mounting table. Results and discussion}

Advanced engineering design capabilities provided by Solid Edge, [10], have been used for solving the 3D modelling task and for the other detailed design activities, [11].

Within the detailed design activities, the design model structuring has been considered as very important, so that the decomposition rules based on functional requirements above mentioned have been mainly targeted to be applied. For providing the Enhanced Product Design effectiveness, efficiency and sustainability, the assembling technology and its importance upon the product's functional qualities has been considered, together with the grouping of components in subassemblies, based on the functional role of the components, for optimizing the general functioning conditions. In developing the CAD models, the constraints imposed by components positioning in the assembly and the mobility degrees of the components in assembly have been also considered. A 3D view and components' identification for the Orienting-Fixing subassembly and its multiplied disposal on the mounting table (Solid Edge 3D parameterized model) are shown in Figure 5.

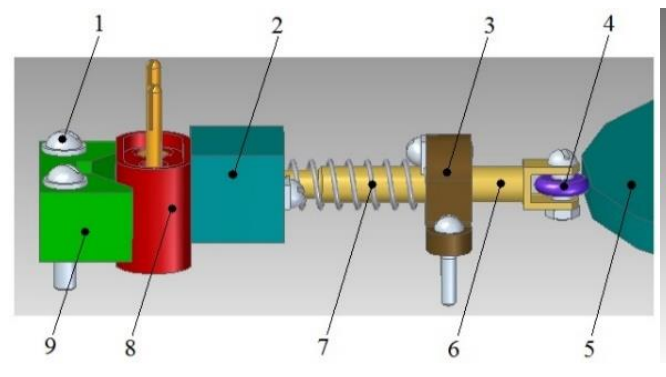

a)

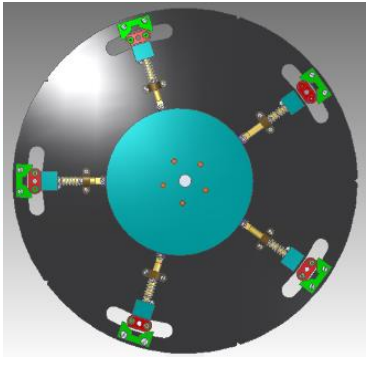

b)

Fig. 5. Solid Edge 3D parameterized models. a) Orienting-fixing subassembly. b) Multiplied disposal of the orienting-fixing subassembly on the mounting table. 1 - screw; 2 - fixing jaw; 3 - guiding element; 4 - roller; 5 - cam; 6 - follower rod; 7 - spring; 8 - plug inlet; 9 - orienting prism.
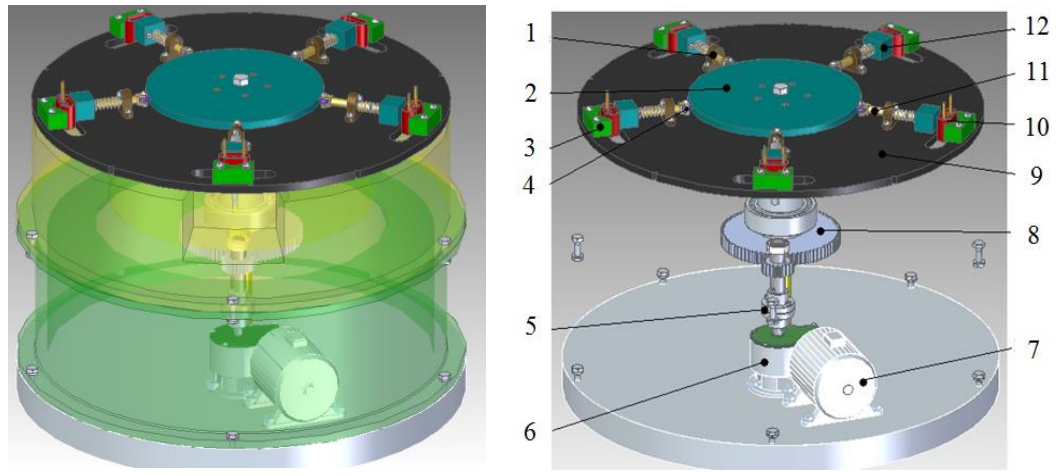

Fig. 6. Assembly 3D view and components' identification for the indexing mounting table (Solid Edge 3D parameterized model). 1 - guiding element; 2 - fixed cam; 3 - orienting prism; 4 - roller; 5 - flexible coupling; 6 - worm gearbox; 7 - electrical motor; 8 - spur gear; 9 - rotary plate; 10 - plug inlet; 11 - follower rod; 12 - fixing jaw. 
The advanced capabilities of the product model dynamic generation and those of its embedded module entitled Engineering Reference, as extremely valuable CAE instrument, have been also used and referred within the presented case study.

An assembly $3 \mathrm{D}$ view and components' identification for the indexing mounting table (Solid Edge 3D parameterized model) are shown in Figure 6.

\section{Conclusions}

The proposed conceptual model for enhancing the effectiveness and efficiency of design activities, by embedment of Axiomatic Design and DfX/DFMA principles is consider as being valuable for defining the client or market needs or demands, which will be translated into product requirements and further on into product specifications.

We can further on conclude here that integrated CAD/CAE/PDM/PLM/DXM software tools like Solid Edge and Velocity Series from Siemens PLM provide enhanced capabilities to develop a product parameterized model characterized by flexibility and easiness in delivering of technical data for new or for modified product versions.

As long as the theoretical approach and the related case study presented in the paper are part of a larger research regarding the optimization of assembled products and assembly processes, we can identify as future research directions the approaching on some other aspects of DfX philosophy and principles within Product/Process Development and also on the Holistic Design philosophy and principles.

\section{References}

1. V. Merticaru, A.C. Paraschiv, M.I. Ripanu, MATEC Web of Conferences 112, 03008 (2017)

2. M. Kressy, Industrial Design (Rhode Island School of Design, Designturn Inc., 2002)

3. N.P. Suh, Axiomatic Design: Advances and Applications (Oxford University Press, New York, 2001)

4. G.Q. Huang, Design for X - First edition (Springer Science, 1996)

5. G. Boothroyd, P. Dewhurst, W.A. Knight, Product Design for Manufacture and Assembly (Marcel Dekker, New York, 1994)

6. D. Stienstra, Introduction to Design for (Cost Effective) Assembly and Manufacturing (Georgia Institute of Technology, USA)

7. V. Merticaru, M.I. Ripanu, M.A. Mihalache, M.M. Cucos, Applied Mechanics and Materials 809-810, 1492-1497 (2015)

8. V. Merticaru, M.I. Ripanu, Applied Mechanics and Materials 371, 499-503 (2013)

9. *** Templatestaff, DFA DFM Analysis Worksheet for Microsoft Excel, (2013) $\mathrm{http}: / /$ templatestaff.com/dfa-dfm-analysis/

10. *** SIEMENS, SolidEdge (2017)

11. I.M. Pista, Bachelor Thesis (TUIASI, 2015) 